\title{
Régimen del gerente de las entidades de economía social y solidaria en América Latina
}

\author{
Manager Regime of Social and Solidarity \\ Economy Entities in Latin America
}

Alberto GarCíA-MülleR*

\section{Resumen}

Este trabajo relaciona el régimen jurídico tanto desde el punto de vista legislativo como doctrinario, en el ámbito latinoamericano, aplicable a la figura del gerente ${ }^{1}$ de las entidades de economía social y solidaria (EESS) como actor fundamental de estas, responsable en gran parte tanto de los aciertos como de los desaciertos que dichas entidades logran.

Palabras clave: administrador, coordinador, director, gerente, secretario ejecutivo.

\section{Abstract}

This paper relates the legal regime from both a legislative and a doctrinal point of view, in the Latin American context, applicable to the figure of the manager of the entities of social and solidary economy (EESS for its initials in Spanish) as its key player, largely responsible for both the successes and failures that these entities achieve.

Keywords: administrator, coordinator, director, manager, executive secretary.

Descriptores alfanuméricos (JEL codes): M120-Personnel Management; Executive Compensation; M540-Personnel Economics: Labor Management; P130-Cooperative Enterprises.

Recibido: 10 enero del 2012 Aprobado: 18 de junio del 2012

Para ubicar el tema es necesario precisar que las EESs tienen sus propias especificidades y que son diferentes de las empresas privadas lucrativas y de las empresas públicas (Bastidas y Richer, 2001). Las empresas privadas - de propiedad y gestión de los inversionistas - tienen por objetivo rentabilizar las inversiones, esto es, la obtención de la mayor utilidad posible de los capitales aportados; las entidades públicas — de propiedad de la colectividad y de gestión de la burocracia estatal- buscan satisfacer las necesidades colectivas (al menos en teoría) sin

Doctor en Derecho. Docente emérito de la Universidad de los Andes, Venezuela. Correo electrónico: agamuller@gmail.com

Llamado también director, coordinador, administrador, secretario ejecutivo.

Cómo citar este artículo: García-Müller, A. (2012). Régimen del gerente de las entidades de economía social y solidaria en América Latina. Revista Cooperativismo \& Desarrollo, 20(101), 90-111. 
que la rentabilidad de estas sea criterio esencial (García-Müller, 1998), mientras que las EEss — de propiedad y gestión de sus asociados-, que son necesariamente rentables, tienen por finalidad prestar servicios a sus propios asociados, quienes son, al mismo tiempo, sus propietarios y usuarios, o sus trabajadores, en el caso de las empresas de trabajo asociado.

La gestión de cada tipo de empresa tiene finalidades distintas: mientras que la gestión de las empresas privadas busca defender los intereses de los inversionistas y las públicas buscan la protección de los intereses de la colectividad en general (García-Müller, 2008), la finalidad esencial de la gestión de las eEss es defender los intereses de los asociados.

De manera que, teniendo las EEss unas características propias (García-Müller, 2012), sus procesos de gestión deben ajustarse a esas particularidades; por esta razón pueden ser mal administradas con los mismos criterios gerenciales del sector privado-lucrativo o del sector público o estatal. Incluso, para garantizar coherencia entre los valores-principios que las animan y las realizaciones prácticas, el sector de EEss debe establecer una carrera gerencial propia.

\section{Fundamento}

En principio, las EESs son gestionadas directamente por sus propios directivos. En efecto, en EESs de pequeñas dimensiones (Álvarez, 2012) o en sus inicios, las funciones ejecutivas, de gestión o de administración, pueden ser asumidas por el órgano directivo o por el presidente de este, superponiéndose — en tal caso- las funciones directiva y ejecutiva. Y muchas veces lo hacen en forma gratuita, lo cual configura lo que se ha denominado como el dirigente "benévolo".

Como dice Nissen,

[...] En principio, los directivos deben dedicar al desempeño de su cargo todo el tiempo y atención que fuera necesario. De manera que la delegación de funciones sólo resulta admisible cuando, por la magnitud de la empresa, sea necesario delegar en alguno de los directores o terceros, en forma total o parcial las funciones ejecutivas de administración (2000, p. 218).

Lovis (1974) señala que si la promoción directa de los cooperadores en el seno de la empresa no permite encontrar los "técnicos gerentes" necesarios, es menester que la cooperativa contrate por lo menos una parte del personal directivo, entre los postulantes que posean las calificaciones profesionales requeridas para cubrir ese puesto.

Ahora bien, aunque la EEss debería ser gestionada solamente por sus miembros, las dinámicas del mercado exigen cada vez más la profesionalización de la gestión, y, en la mayor parte de las veces, la entidad no posee, o no son electos, asociados con capacidad de gestión compatible con el negocio de esta. De allí la necesidad de contratar profesionales externos que deben ser siempre dirigidos y supervisados por el consejo de administración y, en una instancia superior, por la asamblea.

Esta situación, al contrario de lo que parece, no debe ser considerada como un 
desvío del principio de control democrático, pues la acción del profesional debe siempre estar subordinada a los socios a través de los órganos internos. Y aquí surge la figura del gerente.

\section{Concepto}

El gerente puede ser entendido como el encargado de las funciones ejecutivas, de la gestión ordinaria o de la administración directa y cotidiana de la Eess; es el puesto clave de toda empresa.

Ahora bien, existe discrepancia en cuanto al origen de sus facultades:

1. En principio, el gerente es el administrador delegado por el órgano directivo para la gestión empresarial de la empresa. Es un ejecutivo, del mayor nivel jerárquico, sin facultades propias de decisión sino de ejecución de las políticas trazadas por el consejo de administración en materia de operaciones sociales. Sería un mandatario remunerado con autonomía de decisión. Para Kint (1968, p. 231) el gerente debe ser asimilado a un administrador delegado para la gestión diaria.

2. Existe la opinión (Moirano, 2009) de que el gerente no es ni un mandatario ni un órgano social, sino que en realidad se trata de un mero empleado de la empresa, un apoderado general o un factor. Así, la Ley General Chilena de Cooperativas (2002) lo considera como empleado ejecutor de los acuerdos y decisiones del consejo de administración.

Para algunos, la figura del gerente es de carácter facultativo y no constituye un órgano de la organización cooperativa puesto que las prerrogativas asignadas a esta función son delegadas por el consejo de administración (Henry, 2000).

3. Para otros, el gerente es un factor de la EEss, incluso aunque su ámbito de actuación no comprenda la totalidad del ámbito de la actividad de ella o giro y tráfico propio de esta. Como factor de comercio tiene representación suficiente para todos los actos del giro ordinario (Alonso, 2010).

4. El gerente también puede ser considerado como un órgano social en el sentido de que tiene funciones que le son propias (independientemente de la delegación de funciones que pueda hacerle el órgano directivo) siempre que estas hayan sido establecidas por la ley o por la normativa interna de la EESS. De manera que el gerente tiene el carácter de órgano si está previsto en la ley, o si la propia ley autoriza su creación, y esta le asigna determinadas competencias y funciones, o autoriza al estatuto a hacerlo.

\section{Efecto}

El punto tiene que ver con el alcance de las competencias asignadas al gerente, de manera que si es considerado como mandatario, delegado o empleado, las funciones que ejerza serán -única y exclusivamente- las transmitidas por el órgano directivo, sujetas, además, a las limitaciones o extensiones que en cualquier momento este pueda hacer. En cambio, si el gerente es considerado cargo u órgano, sus funciones serán las estable- 
cidas en la normativa correspondiente, las que ejercerá por poder propio, que no pueden ser limitadas por el órgano directivo, y tampoco extendidas motu proprio.

\section{Doble relación}

El gerente profesional tiene una doble relación con la EEss, así:

1. Por un lado, tiene una relación contractual ya que puede ser considerado como un apoderado, mandatario, representante o delegado del órgano directivo que actúa por la empresa y hace recaer en esta las gestiones que realiza en su nombre.

Ahora bien, si la ley o el estatuto (por permisión legal) le otorgan al gerente competencias propias, ya no tendría relación contractual sino el carácter de un cargo dentro de la empresa, entendiéndose por tal un conjunto de potestades y de derechos atribuidos a una unidad operativa de la organización, y la relación sería de carácter institucional u orgánico.

Además, si el gerente es considerado por la ley o el estatuto como representante legal de la empresa, asumiría, entonces, el carácter de órgano. Esto es, aquella parte de la estructura organizacional de la empresa que actúa en nombre de ella, y que hace recaer en ella las decisiones que adopte en su nombre.

2. Pero nada obsta a la existencia de una relación de dependencia entre EESS y gerente si se configuran las notas caracterizantes del contrato de trabajo, ya que al margen de su función institucional quien lo desempeña realiza tareas estrictamente personales de carácter subordinado (Verón, 2009). Sin embargo, ello no es así en las empresas de trabajo asociado si quien desempeña la gerencia es un asociado-trabajador de ella, ya que, precisamente, el ejercicio de la función gerencial sería la prestación de actividad laboral que esa persona realiza en la empresa.

\section{Trabajador de dirección y confianza}

Parece que lo más acertado es considerar al gerente como un trabajador de dirección o de confianza, unido a la empresa por una relación laboral. Lo es en cuanto el gerente es aquel trabajador que por su ca rgo y por las funciones que presta tiene una gran responsabilidad dentro de la estructura administrativa de la empresa; tiene conocimiento personal de secretos industriales o comerciales, y en cuanto posee mando y jerarquía frente a los demás empleados; actúa como representante del patrono o empleador $\mathrm{y}$ en tales condiciones sus actuaciones frente a los demás empleados obligan al empleador o patrono, en el caso, la EEss.

La calidad de trabajador de dirección y confianza puede ser expresamente contemplada en el respectivo contrato de trabajo, pero si así no se hiciese, lo que prima no es lo enumerado en el contrato, sino la naturaleza de las funciones que se cumplen; lo que significa que la condición de ser empleado de dirección y confianza no está dado por el contrato en sí, sino por las funciones desempeñadas por el empleado, puesto que así no figure en el contrato, ha sido la voluntad del empleador el asignarle 
ese tipo de funciones. Fue su voluntad que el empleado le representara ante los demás trabajadores, tal y como lo señaló la Corte Constitucional de Colombia, en Sentencia C-593 de 1993 (República de Colombia, Corte Constitucional, 1993).

Se trata de una única persona que se encuentra en el "vértice organizativo" de la entidad, en relación directa — de primera mano- con el órgano directivo, de quien recibe instrucciones y criterios referidos al conjunto de objetivos generales o los aspectos trascendentales de la empresa. Ejerce esos poderes con autonomía y responsabilidad, en una posición relevante de poder sobre toda la organización. A su vez, imparte instrucciones a otros trabajadores que pueden ejercer funciones directivas en sus ámbitos funcionales o geográficos de actuación - directores de sistemas, recursos humanos, finanzas, consultores jurídicos-, quienes son trabajadores ordinarios de confianza, al igual que los jefes de departamento que dependen directamente de ellos (Márquez, 2002).

\section{Relación del gerente con la EESS de acuerdo con su naturaleza}

Existen tres tendencias principales, a saber:

- Mandatario: Contrato de mandato regulado por la legislación civil.

- Empleado: Contrato laboral regido por la legislación laboral.

- Ejecutor: Relación asociativa normado por la legislación de ess.

\section{Características}

1. El cargo de gerente es de carácter unipersonal o individual, aunque pueda existir una pluralidad de ellos, pero - en todo caso- de segundo nivel o subordinados a este.

2. El gerente normalmente no está sometido a las limitaciones de duración de la jornada de trabajo, ni a la aplicación de las convenciones colectivas. Si las condiciones de trabajo así lo exigen, el trabajador de dirección y confianza deberá trabajar más de la jornada legal, pues al estar la empresa bajo su responsabilidad, no puede ausentarse de ella mientras que las obligaciones exijan su presencia. Y como empleado superior y asumiendo responsabilidades relativamente pesadas, no puede pretender el pago de horas extraordinarias (Issert, 1958), ello porque representa los intereses del patrono más que los intereses de la fuerza laboral. Se trata de una relación signada por la confianza, en la que las normas comunes de la extinción del contrato de trabajo se antojan inapropiadas por ser demasiado rígidas. Pero, además, goza de una amplia autonomía en el cumplimiento de sus funciones, siendo su subordinación al patrono menos intensa (Márquez, 2002).

3. Es de absoluta confianza del consejo de administración, de su libre nombramiento y remoción en cualquier momento, incluso sin mediar una causa objetiva justificada, sino meramente por perder la debida confianza de los integrantes del órgano directivo (ad nutum).

4. El ejercicio de sus funciones es de carácter personal e intransferible, aunque pueda encargar funciones 
específicas, de carácter parcial, a personas determinadas, en lo posible, bajo normativa específica.

5. Salvo que diversamente se hubiera establecido en el estatuto o reglamento, o estipulado en el acto de su designación, la duración del gerente en el cargo es de plazo indeterminado, aunque nada impide que se celebren contratos por tiempo determinado, renovables por común acuerdo de las partes; sin embargo, el contrato puede ser transitorio, e incluso rotativo, por periodos breves en que los miembros de la empresa se van turnando su ejercicio. "La duración de las funciones del gerente será determinada en el estatuto. Si este nada dicen al respecto, el mandato del gerente será a duración indeterminada" (Kint, 1968).

Ahora bien: la duración de la misma persona en la función gerencial debe ser "prudencial", en el sentido de que sea lo suficientemente amplio como para ejecutar un programa completo de gestión, pero no tan largo como para que - por la vía de la permanente continuidad- la organización se acostumbre al mando permanente de una misma persona, y esta se amañe en el ejercicio del poder en la empresa.

6. El sustituto temporal del gerente (vacaciones, permisos, etcétera) lo nombra el órgano que lo designó.

\section{Designación}

El gerente puede ser designado:

1. Por los órganos internos: por la asamblea, lo que es aconsejable en empresas de dimensiones pequeñas, en entidades de trabajo asociado, o en las que la participación de los miembros es intensa (en las UBPC de Cuba es electo por la asamblea). Sin embargo, lo normal es que tanto sea asociado como personal externo, sea designado por el órgano directivo, con aprobación del órgano de control interno.

2. De forma temporal, por una entidad externa que puede ser el organismo de integración, el ente que ejerce la tutela de la empresa en la etapa previa o cuando ella se encuentre en procesos de recuperación empresarial, por la cabeza del grupo empresarial en que participe la empresa, o por el interventor.

Su designación por la autoridad de aplicación, por la entidad de fomento o por la que otorgue financiamiento, representa una evidente violación de la autonomía de la EEss.

\section{Requisitos}

"El estatuto —o reglamento especialdebe establecer qué condiciones mínimas debe reunir [el gerente], las garantías que se le exigirán, la remuneración a la que tendrá derecho, sus obligaciones, atribuciones y facultades, entregándole en lo posible la total responsabilidad de la marcha administrativa de la institución" (Yuri, 1956, p. 130).

Para ser gerente se destacan los siguientes requisitos:

1. Poseer un título profesional en materia de administración, contabilidad o economía, o tener la competencia y 
los conocimientos técnicos y sociales necesarios (se tiende a profesionalizar o especializar la gestión y crear una carrera gerencial solidaria).

2. Prestar garantía o caución personal o real para responder por sus actuaciones (se discute a cargo de quién debe estar el coste de esta, si de la empresa o de la persona del gerente, así como su umbral financiero).

3. No ejercer al mismo tiempo un cargo directivo en la propia empresa y no tener vínculo de consanguinidad o de afinidad con alguno de los directivos, salvo que el número de miembros no lo permita.

4. Requisitos subjetivos: honestidad, espíritu cooperativo o solidario, gozar de la confianza de los miembros.

5. Se le puede exigir la diligencia de un gestor y la necesaria lealtad y fidelidad en el desempeño de su cometido, así como prohibir dedicarse por cuenta propia o ajena al mismo tipo de actividad económica a la que se dedica la empresa, durante el desempeño de su cargo.

6. La designación del gerente puede ser seguida de la obligación de inscribir el nombramiento en registros especializados llevados por la autoridad de aplicación, por los colegios o las corporaciones profesionales o por los organismos de integración.

\section{Capacidad}

Es un hecho cierto que la función gerencial en las empresas de EESs es más compleja que la requerida en las empresas lucrativas o estatales, ya que, como señala Dávila (2005), además de las funciones primordiales que normalmente tienen los gerentes de estas empresas en relación con la administración — planeación, decisión, organización, dirección y control- y de coordinación de áreas específicas -finanzas, mercados, producción de bienes y servicios y dirección del personal- deben asumir funciones socioeconómicas —orientación para administrar el equilibrio económico y social—, de movilización social —comunicación, educación, movilización y participación-y habilidad empresarial -innovación, intercooperación y desarollo comunitario.

El conjunto de exigencias que tienen los gerentes en las EEss, presupone que estos deben estar técnicamente capacitados, por lo que es deseable que tengan compromiso con los intereses de los asociados y de la entidad, experiencia para el ejercicio de la función que les corresponde, habilidad para conducir, motivar y trabajar en equipo y capacidad para la toma de decisiones. Es más, como señala Mateo (2005), el gerente debe conocer, en todo momento, que sus acciones dependen de la planificación aprobada por los socios, que son al mismo tiempo usuarios o trabajadores de las cooperativas, y debe subordinar sus acciones a las directrices adoptadas democráticamente por la asamblea y controladas en su cumplimiento por los consejos rectores.

En las empresas de trabajo asociado, salvo casos muy poco frecuentes, al asociado trabajador a quien se le asigna 
el ejercicio de la función gerencial no se le pueden exigir cumplir requisitos de profesionalización, salvo que la propia empresa estimule la formación profesional de sus asociados, actividad que - en todo caso- debe tener prioridad.

Por otra parte, para América Latina parece igualmente cierta la afirmación de que en verdad la falta de suficiente personal competente de gerencia probablemente sea el factor limitador más serio para el mayor crecimiento y expansión de la actividad cooperativa en Estados Unidos. Pero no hay impedimento para crear el creciente acopio de personal competente de administración que se necesita en los niveles nacional, regional y local de las empresas cooperativas (Cooperative League, 1973).

\section{Procedencia}

La adscripción de gerentes competentes no se logrará incorporando personal procedente de empleos en otros negocios, pero ajenas al sector. Es más, ello no es lo más conveniente por cuanto la mayor parte de estas personas están sumergidas en los valores y principios de la sociedad de consumo, con el supremo valor del éxito personal tarifado en la remuneración y en la adquisición de un elevado nivel de vida basado en la posesión y el disfrute de bienes y servicios. Los mejores de ellos son ciertamente competitivos en el mercado de trabajo de la sociedad globalizada de acuerdo con patrones mercantilistas, y van a reflejar esos valores y esos principios en la dirección y gestión de las Eess.
De ello se deriva una verdadera contradicción: las cooperativas, mutuales (García-Müller, 2002) y demás formas asociativas tienen unos valores y principios "históricos": solidaridad, equidad, ayuda recíproca, servicio, beneficio colectivo, etcétera, que son diametralmente opuestos a los que traen estos profesionales y que son, entre otros, rentabilidad, eficiencia, optimización de la utilidad, etcétera, y que, en efecto, tratan de implantar en ellas, produciéndose una verdadera desnaturalización. El único modo seguro de pertrechar las actividades de la empresa cooperativa con el tipo de administración que necesitan, es mediante el desarrollo de las capacidades de las personas con que cuenta actualmente y su promoción, antes que esperando que tales personas les "caigan en el regazo" procedentes de otras fuentes.

\section{Revocación}

"El gerente, como todo mandatario, es revocable por la autoridad que lo ha designado, lo que le da derecho a percibir la indemnización prevista por la legislación laboral, habida cuenta de su calidad de dependiente" (Althaus, 1974, p. 484). Sin embargo, algunos otros sistemas legales, al considerarlo como trabajador de dirección, no le conceden indemnización por el despido. Ello no es el caso de las empresas de trabajo asociado, en las que al asociado trabajador que es revocado del cargo de gerente por cualquier causa, pasa a desempeñar otra función en la empresa. 
De su lado, podrá dimitir en las mismas condiciones que un administrador, (Kint, 1968) debiendo permanecer en el ejercicio de sus funciones hasta tanto sea provisto su reemplazo.

Pensamos que debería atribuirse a la asamblea la potestad incondicional de remover al gerente - incluso sin necesidad de estar previsto en el orden del día-, de manera que se pueda cambiar a un gerente "enquistado" en su cargo, y así poder contar con la complicidad -intencional o negligente- del órgano directivo.

\section{Remuneración}

El principio general en la materia es que el gerente debe ser adecuadamente remunerado por el ejercicio de sus funciones. Es una realidad que un buen gerente es la mejor inversión, pero costosa, por lo que una Eess pequeña no podría pagar un buen gerente, aunque varias EESS unidas sí podrían hacerlo, compartiendo tiempos de este y uniendo actividades.

La remuneración del gerente está compuesta por dos partes: directa e incentivos y desincentivos.

La remuneración directa está integrada por:

1. El salario, que debe guardar proporción tanto con el nivel de preparación del gerente y las funciones que ejerce, como con la situación económico-financiera de la empresa en particular, en las diversas etapas de su ciclo vital. Pero, además, debe tomarse en cuenta el llamado intervalo remunerativo, entendido como la diferencia en la escala de remuneraciones que perciben los trabajadores de una empresa, que no debería superar una proporción de uno a seis salarios del menor al mayor nivel.

Ahora bien, cuando el cargo de gerente es ejercido por un asociado trabajador de una entidad de trabajo asociado, su remuneración no puede ser considerada como salario sino como anticipo laboral, cuyo monto será determinado según las escalas establecidas en la reglamentación interna.

2. Las prestaciones sociales de acuerdo con la legislación laboral ordinaria.

3. Seguridad social integral, constituida tanto por la seguridad social universal y obligatoria, como por las coberturas adicionales.

\section{Incentivos y desincentivos}

Como señala Celebrón (1998), deben analizarse las relaciones y los incentivos entre el principal —aquel que encarga al agente desarrollar un determinado encargo y lo supervisa, en el caso, el consejo de administración - y el agente, quien debe ser adecuadamente incentivado para que encuentre conveniente optimizar sus funciones en provecho del principal.

De tal forma que el gerente debe recibir:

1. Participación en excedentes como cualquier asociado, en el caso que lo fuese.

2. Incentivos por productividad, por asiduidad o por competencia en el ejercicio de sus funciones. Puede ser mediante el pago de un porcentaje, —calculado sobre el volumen de operaciones-o por la utilidad marginal 
obtenida por la empresa a partir de una base de negocios determinada.

3. En el caso de la prima sobre cifra de negocios, el código rural francés dispone que en ningún caso podrá ser asignado un porcentaje sobre cifra de negocios realizados por la sociedad, por lo que el Tribunal declara la nulidad absoluta del contrato de trabajo entre el director y la cooperativa, acordando al primero un salario basado sobre la cifra de negocios de la cooperativa, y que la norma es una prescripción imperativa de interés del orden público.

\section{Distribuciones patrimoniales irregulares}

Son actos de disposición realizados por la empresa a favor de uno o más miembros (aplicable al gerente) por razón de su condición de tales y al margen de los procesos regulares de distribución del activo, siempre que por medio de estos se otorgue una ventaja o un enriquecimiento de carácter patrimonial. Puede tratarse de préstamos excepcionales; remuneraciones desproporcionadas con la situación financiera de la empresa; uso de bienes de la empresa a efectos personales o no relacionados con el objeto social; pago de gastos innecesarios o suntuosos; otorgamiento de fianzas u otras garantías de obligaciones asumidas por terceros (Vasquerizo, 1998).

De incurrirse en las prácticas anteriores, deberían aplicarse sanciones disciplinarias a los responsables; surge la obligación de reintegro a la empresa, y si se causan daños al patrimonio de la entidad, los culpables deberían responder en forma solidaria e ilimitada.

\section{Competencias del gerente}

Puede ser que la ley no establezca la figura del gerente, ${ }^{2}$ que no determine las competencias de este o que lo hiciere en forma genérica. En cualquier caso, sus competencias o funciones deberían ser estipuladas en forma expresa en el estatuto, en un reglamento interno o, de forma escrita, en el acto de su designación.

Las competencias del gerente pueden ser propias o delegadas. Las competencias son propias cuando han sido fijadas en la normativa, sea esta la ley, el estatuto, el reglamento interno o un acuerdo de la Asamblea, y son delegadas aquellas que, no siendo de su propia competencia, le han sido transmitidas por el órgano directivo. Entre ellas está la defensa de los intereses de los asociados, y otras que analizaremos en los siguientes apartados.

\section{Defensa de los intereses de los asociados}

La primera y esencial función del gerente es la defensa de los intereses de los miembros de la empresa. Plantea Hübenthal, citado por Sánchez (1992), que la promoción de los asociados es el objetivo que justifica la existencia de la cooperativa. Al ser el objetivo principal de esta promocionar a sus dueños a través de los servicios que presta, las decisiones administrativas tienen que formarse dentro del margen de ese cometido superior. De forma que

\footnotetext{
2 Siete leyes de eEss de América Latina no contemplan la figura del gerente (ver tabla 1.).
} 
el principal cometido de la gerencia de la EESS es producir - en forma crecienteventajas para los asociados, evitando la discriminación.

Ahora bien, como señala Vargas (2009) durante mucho tiempo se supuso que los administradores actuarían buscando únicamente el beneficio de los asociados ejerciendo sus funciones en calidad de administradores fiduciarios; sin embargo, las cosas han evolucionado de manera diferente y la supremacía de los administradores con objetivos propios se ha hecho sentir en toda la organización, de tal manera que muchos autores nos hablan del peligro de una dictadura de los administradores sobre los asociados.

Así que, como dice Parnell (1993), en las EESS se presenta un conflicto entre los gerentes remunerados que tienden a perseguir el crecimiento y la rentabilidad de la empresa, y los directivos (como representante de los miembros) que esperan que su organización cumpla sus propios objetivos, esto es, la prestación de ventajas para el grupo o la satisfacción de sus necesidades con la máxima eficacia y eficiencia. Este foso entre los objetivos perseguidos por los dirigentes asalariados y el de los dirigentes electos puede ser muy profundo.

El gerente se refiere a los objetivos de la empresa en términos "comerciales", mientras que los dirigentes lo ven bajo el aspecto social o ético. En el fondo, existe un desequilibrio entre el poder real del dirigente a tiempo parcial y el profesional a tiempo completo que controla toda la información y los recursos; existe un conflicto de intereses entre ambos que pudiesen ser controlados (nunca suprimidos) mediante la separación de funciones de ambos poderes, asignando actividades específicas a cada uno y evitando con ello superposiciones o solapamientos.

\section{Separación de funciones}

Como señala Mora (1992), persisten insuficiencias en la definición más precisa del engranaje de vinculación de la esfera administrativa y las premisas democrático-administrativas de las cooperativas, sobre todo en los niveles de gestión, de la toma de decisiones y en la pronta adaptación a las condiciones cambiantes del entorno.

Entonces, como lo plantea Schneider (1999), con la progresiva transferencia de funciones de la asamblea a órganos especializados, crece también la necesidad de establecer una clara distinción entre la política de decisiones y la política de ejecución en las grandes EEss y en las entidades de integración. De la primera se encargarían los consejos de administración, cuyos integrantes, como dirigentes electos por la asamblea, definen las grandes líneas políticas de acción y sus prioridades y tienden a asumir cada vez más una función de supervisión y de control sobre la máquina administrativa.

De esta forma, el órgano directivo es el responsable de la conducción mayor y más importante de la empresa, según los lineamientos generales dados por el órgano deliberante, y la realización de los objetivos se hace a través del órgano ejecutivo (Schujman, 1969). Las determinaciones a tomar día a día para 
plasmar los objetivos y fines generales, bajo la conducción del órgano directivo, corresponden al órgano ejecutivo (García-Müller, 1997).

En este sentido, tal y como señala la OIT (2002), las leyes más recientes suelen estipular que el consejo de administración se limite a definir el marco político y un plan de trabajo para la cooperativa, $y$ que la aplicación efectiva de esta política se lleve a cabo por parte del personal profesional de dirección.

En forma más concreta, Parnell (1993) propone la aplicación de los siguientes criterios:

1. Las funciones de representación y comunicación con la base deben ser de un staff diferente al de los administradores.

2. El consejo de vigilancia debe asegurarse de que la entidad se concentre en su finalidad, que es obtener los objetivos sociales (Durán, 2004).

3. El consejo de administración debe equilibrarse de forma que el poder no se concentre en uno o dos individuos, sino que la competencia de los gerentes se compense con la de los dirigentes.

4. La revisión de cuentas debe ser independiente y referirse directamente a la asamblea, encargarse a profesionales independientes y cualificados y tener el apoyo completo de los revisores internos.

\section{Asignación de actividades}

El órgano directivo vela por los objetivos de la organización y su ejecución en nombre de los asociados. Por ejemplo, son de su competencia la planeación, las relaciones con los asociados y con el público en general, la responsabilidad a medio y a largo plazo por las instalaciones, finanzas, la política de mano de obra, etcétera.

De segundo, cuidan a los gerentes que, siendo especialistas, conducen la máquina administrativa y cuidan las decisiones y actividades prácticas y corrientes en materia de gestión a la luz de las instrucciones recibidas del consejo de administración. Asimismo, se responsabilizan directamente de las relaciones con los funcionarios y empleados y de todos los procesos de producción, industrialización y comercialización.

En tal sentido, recientes leyes demarcan los poderes inalienables de los órganos de la cooperativa de los que tienen los cada vez más profesionalizados administradores. De esta forma, lo relacionado con el carácter asociativo es decidido por la asamblea. Las grandes líneas de negocios son decididas por los directivos, mientras que los gerentes toman las decisiones diarias bajo la supervisión del grupo de directivos (Henry, 2002).

El gerente es el ejecutor de los acuerdos y las órdenes del consejo de administración, a quien le corresponde la supervisión y aprobación de actos de la gerencia, así como el control de los objetivos y la conformidad de los resultados con estos. Por esta razón, la legislación debería incluir disposiciones que garanticen la transparencia de los acuerdos de dirección y el proceso de 
adopción de decisiones, y que ayuden a mantener la naturaleza democrática de la adopción de decisiones en la cooperativa (OIT, 2002).

\section{Gestión ordinaria}

Corresponde a la gerencia asumir la administración directa y la gestión diaria o asidua de la empresa en sus aspectos administrativos, contables, técnico-productivos, comerciales y financieros, esto es, los asuntos concernientes al giro o tráfico empresarial ordinario.

Asimismo, debe conservar los bienes sociales, mantenerlos en el patrimonio social, justificar su transmisión y mantener su producción en el activo, o bien dar cuenta de su destino o aplicación por medio de su registro, en la contabilidad. Sin embargo, no puede disponer de fondos patrimoniales, no solamente mediante un acto fuera del objeto social, incurriendo en distribuciones patrimoniales irregulares (Vasquerizo, 1998), ni "notoriamente extraño" a este.

Entre sus principales atribuciones se encuentra asumir la responsabilidad por los estados patrimoniales y resultados de la organización, ya que estos documentos sintetizan los resultados obtenidos por ella. También es su función reunir y exponer al órgano de dirección las vulnerabilidades y los riesgos de la empresa).

Como señala Ciurana (1968, p. 259), las cooperativas francesas de consumo adoptaron el sistema de los gerentes responsables, con fianza, con una participación sobre las ventas del cuatro al seis por ciento y que administra libremente su tienda (sucursal cooperativa), contratando libremente a sus empleados, pero respetando los precios fijados por la central.

\section{Dirección de personal}

Corresponde al gerente escoger y contratar el personal necesario, establecer sus deberes, señalar su remuneración dentro de la escala establecida por el órgano directivo, delegar autoridad y responsabilidades, supervisar su desempeño, evaluarlo, promoverlo y aplicar sanciones disciplinarias, incluso despedirlo. Si el órgano directivo se reserva alguna atribución en materia de personal, debe establecerlo expresamente en la normativa correspondiente (García-Müller, 2009).

\section{Asesoría}

Salvatierra (2011) señala que es de suma importancia la decidida participación del gerente de la cooperativa, en su rol como asesor principal de la asamblea, los consejos y comités. Al ser el funcionario del más alto nivel, y por la misma confianza delegada por el directorio, el gerente debe asumir con plena propiedad la conducción empresarial de la entidad, orientando en forma transparente, honesta y profesional, el desempeño eficaz de los diversos estamentos que componen la parte asociativa, apuntando a conciliar criterios, tanto técnicos como de carácter social, y equilibrando las estructuras de poder interno hacia una buena gobernabilidad (Torres y Maza, 2004; Cracogna y Uribe, 2003).

Y añade: a veces la gerencia se inhibe de involucrarse con la parte dirigencial, desconociendo su papel de asesoramiento técnico, para justamente ayudar a la 
toma de decisiones de aspectos que luego repercuten en su accionar ejecutivo. En otras ocasiones, los directivos descartan o se eximen de convocarlo para tratar temas y áreas que, por su misma condición de directores que se reúnen una vez al mes, no se encuentran debidamente informados y tienen poco conocimiento sobre determinados rubros.

\section{Representación}

En muchos casos, el gerente ejerce la representación legal de la empresa, la que puede ser general (para todos los actos y gestiones de la empresa), o especial, para casos expresamente especificados, por delegación expresa del órgano directivo.

El poder de representación de la empresa por parte del gerente depende de que el texto legal le atribuya o no esa función. Cuando no le otorga dicha función, el gerente sólo puede obligar a la sociedad en la medida del otorgamiento de un mandato por esta, mas este no puede ser sustitutivo de la función representativa legal ejercida por el órgano determinado en la ley o el estatuto, por lo cual su representación no puede ser general, sino para actos específicamente determinados.

Debe estudiarse con mucho cuidado el alcance del poder de representación legal del gerente (Gagliardo, 2007). En principio, lo tendría para los actos que involucran la esfera de los actos propios del manejo de la firma, sin desplazar al representante legal, quien asumiría la representación de la entidad en los actos de disposición o de administración extraordinaria.

\section{Ejecución de las decisiones del órgano directivo}

El gerente ejerce funciones ejecutivas de la administración de manera continua y con especialidad, con el alcance y la forma que instruya el consejo de administración, sea por el objeto de explotación o por imponerlo la organización interna de la empresa. Obedece las resoluciones del consejo, siempre que no violen la ley, el estatuto o las resoluciones de la asamblea (Verón, 2009). El órgano directivo sólo puede funcionar y ejercer autoridad como grupo reunido: los directivos no pueden asumir personalmente la autoridad fuera de las reuniones - periódicasde aquel (Thomas, 1962).

\section{Relaciones entre el gerente y los directivos}

San Pedro (1984) señala que es indudable que los consejos de administración de las cooperativas tienen facultades indelegables, pero, como en todo tema polémico, se presentan dos situaciones extremas:

- Una puede consistir en que, por comodidad, rutina o inoperancia del consejo de administración, el gerente y el equipo de funcionarios superiores asuman las facultades de aquel y en la práctica lo sustituyan convirtiendo al consejo en una estructura formal, cuya función se limita a legalizar lo que hace la gerencia (Alonso, 2001).

- En el otro extremo están quienes consideran que su autoridad se fortalece minimizando la función gerencial, limitando las facultades del gerente e 
ignorando sus opiniones y las de los funcionarios superiores.

Por otra parte, aunque en cualquier empresa una relación abierta y sana entre la junta directiva y el administrador de esta es esencial, en las entidades de EEss existen determinadas condiciones que hacen que esta relación sea particularmente vulnerable: sus miembros ocupan sus cargos como representantes de los asociados en lugar de que sea debido a su inversión económica personal; raras veces son personas preparadas en asuntos de negocios, y la propiedad y el control de la entidad las identifica con procesos democráticos.

De manera que en las cooperativas es esencial -entonces- que tanto los directivos como el gerente tengan delimitados sus deberes y responsabilidades, los conozcan, respeten y comprendan. El asunto crucial es la división y asignación de responsabilidades y de autoridad entre el órgano directivo y el ejecutivo. $\mathrm{El}$ hecho es que existen insuficiencias en la definición más precisa del engranaje de vinculación entre la esfera administrativa y las premisas democráticas de la empresa, para cuya superación Thomas (1962) ha delimitado los deberes de ambas partes como se describe en los siguientes apartados.

\section{Deberes de los directivos respecto del gerente}

- Definir la política de gestión: determinar los objetivos en un plazo de acción y los medios que serán puestos a disposición del director. En conse- cuencia, debe controlar la aplicación y los resultados de la actuación que él mismo ha determinado y tomar las decisiones de ajuste que se impongan (Molina, 1968).

- No usurpar las tareas de ejecución que no son de su incumbencia. En especial, deben hacer respetar en todo momento la autoridad jerárquica del director, único depositario del mando sobre el personal de la cooperativa y responsable de la utilización del material de la sociedad, conforme con los fines cooperativos.

Como señala Paradis (1993), el desglose de responsabilidades entre el presidente de la junta directiva y las propias del gerente debe ser muy claro. Lo que es cierto es que no es un "mandado" que necesite ser supervisado diariamente. Debe responder y gozar de autoridad, autonomía y medios para cumplir su mandato hasta el final.

- El consejo debe asegurarle al director un estatuto apropiado en relación con sus deberes y responsabilidades; darle la gran importancia a su remuneración, pago de sus competencias y estímulo para una gestión sana (Molano, 2011).

\section{Deberes del gerente respecto de los directivos}

- Preparar los elementos objetivos de decisión. No ejercer funciones deliberativas.

- Rendir cuentas con claridad y precisión. 
- Ayudar a los directivos a perfeccionar su conocimiento en materia de gestión, especialmente en lo que concierne a las cuestiones financieras y contables (Muños, 2006).

- Proporcionar al órgano directivo la información que se necesite para la planeación a largo plazo.

- Recomendar a los directivos metas específicas y realistas para la empresa.

- Ayudar al consejo a establecer políticas, reglamentos y programas para que sean aprobados antes de ponerse en ejecución.

\section{Responsabilidad del gerente}

\section{Responsabilidad personal del gerente por el desempeño de su cargo}

Generalmente es aceptado (CEA, 1968) que la responsabilidad que le corresponde al gerente es por norma la responsabilidad civil de derecho común de los comisionistas y, al ser su contrato de mandato, responde no sólo por dolo sino también por la culpa en su ejecución.

Como delegado del consejo de administración responde ante él y, en consecuencia, por sus actos responde este consejo, quien a su vez responde al consejo de vigilancia a rendirle cuentas a la asamblea de los actos que ejecute este (Ardiles, 1979, p. 270).

Para que proceda la responsabilidad personal del gerente deben darse las siguientes premisas:

1. La existencia de un vínculo laboral que exige deberes de obediencia y de respeto a la autoridad natural de la empresa, aunque la relación jerárquica entre consejo de administración y gerente carece de la estrictez militar para que ante una orden de aquel, este pueda ampararse en la causal de "obediencia debida".

2. El gerente debe realizar sus funciones con la diligencia de un ordenado gestor $\mathrm{y}$ de un leal representante, $\mathrm{y}$ responde por cualquier perjuicio que cause a los intereses de la cooperativa por haber procedido con dolo (Morgado, 2012), negligencia, exceso de facultades o infracción de las órdenes o instrucciones que hubiera recibido del órgano directivo (Sanz Jarque, 1994).

3. La responsabilidad puede ser personal por dolo o por culpa en la ejecución del mandato o el ejercicio de sus funciones propias, siempre que cause daño a la entidad: "la responsabilidad que le corresponde al gerente o director es, normalmente, la responsabilidad civil de derecho común por violación de ley, del estatuto o de las funciones asignadas —o delegadas por el órgano directivo- en el acto de su designación” (Sanz Jarque, 1994).

Como lo ha dicho la Casación Francesa (citada en Issert, 1958, p. 71), el director asalariado empleado al servicio de una sociedad cooperativa resulta responsable de las faltas que ha podido cometer en el ejercicio de sus funciones, y está obligado a reparar las consecuencias perjudiciales a su empleador.

4. Son casos de responsabilidad personal del gerente, entre otros, ejecutar actos contrarios a los intereses de la empresa, 
o permitir su ejecución aún cuando ello signifique no ejecutar aquellos acuerdos tomados por el consejo de administración que pudieren dar un resultado claramente perjudicial en el patrimonio social (Rodríguez y Cedeño, 1991, p. 23).

5. Se excluye su responsabilidad tributaria, salvo que se trate de la práctica de un ilícito cometido por él mismo contra la propia empresa (Correa, 2003) o por la práctica de un crimen, en cuyo caso sería personalmente responsable (Álvarez, Gordo y García, 2009).

\section{Responsabilidad de la empresa por los actos que ejecute el gerente}

El principio es que ni la Eess como persona jurídica ni el consejo de administración como mandante pueden sustraerse de responder ante terceros por el ejercicio de los poderes que le han sido conferidos al gerente, lo cual es su responsabilidad solidaria, siempre y cuando se compruebe que los sujetos a quienes se atribuye dicha actuación han desempeñado de manera efectiva las funciones de administrar (Rodríguez y Cedeño, 1991).

Y la entidad no puede exonerarse de culpa probando su falta de culpa, ya que la delegación de la autoridad en funciones ejecutivas a favor del gerente no elimina la responsabilidad de los directivos como administradores legales y naturales de la entidad (Verón, 2009).

Esa responsabilidad de la empresa por los actos del gerente (Pastor, 2007):
1. Es de carácter reflejo, es decir, por extensión, y responderá por los actos ilícitos practicados en ejercicio o con motivo de la función del gerente en un marco de adecuada razonabilidad, acorde con las circunstancias del caso, por lo que se dice que no hay responsabilidad de la empresa por extralimitación del gerente.

En tal sentido, los actos que lleva a cabo el gerente mandatario con extralimitación de las facultades legales que el mandato conferido por el consejo de administración le otorga, no obligan a la cooperativa aún cuando los terceros contratantes lo hicieran de buena fe, por cuanto estos se encuentran en la obligación de prever los alcances de los poderes con los que actúa su contraparte, toda vez que su falta de previsión no puede ser imputada al consejo de administración (mandante) que en este caso no tiene culpa alguna con respecto a la extralimitación del gerente (Rodríguez y Cedeño, 1991).

2. En contra, Verón (2009) opina que la responsabilidad surge a raíz del desempeño de las funciones confiadas, sin que importe que el gerente haya obrado o no con sujeción a instrucciones recibidas, por lo que dentro del campo de sus funciones específicas responde la cooperativa. Si el dependiente se aparta de las instrucciones recibidas, subsiste la responsabilidad refleja del empleador, por haber omitido utilizar los medios correctos para mantener al dependiente en el cauce adecuado. 
3. Los directivos podrían compartir responsabilidad por los actos que ejecute el gerente, que sería accesoria al personal de este (Soveral, 2002). Es factible atribuir responsabilidad civil subjetiva indirecta in eligendo o in vigilando a los miembros del consejo que nombren a una persona decididamente incapaz para el cargo de gerente, o que una vez nombrada esta, no controlen la actuación de quien es un subordinado (Rodríguez y Cedeño, 1991).

4. Incluso, ni la empresa ni los directivos pueden sustraerse de responder solidariamente ante terceros por actos del gerente, estando su plazo vencido, habiendo sido removido, o cuando aún no ha sido nombrado, siempre y cuando se compruebe que ha desempeñado de manera efectiva las funciones de administración (Rodríguez y Cedeño, 1991).

\section{El gerente en las leyes de economía solidaria de América Latina}

Del análisis comparativo de la legislación latinoamericana de Eess (tabla 1) podemos concluir que el régimen jurídico del gerente es deficiente por las siguientes razones:

1. Una tercera parte de las leyes desconoce la figura del gerente: de las 26 leyes de EEss analizadas, 20 hacen referencia expresa a la figura del gerente, y seis no.

2. Es totalmente diversa la naturaleza jurídica reconocida por las legislacio- nes al gerente: seis leyes lo consideran como delegado del consejo de administración; cinco como empleado del mismo, tres le otorgan la condición de "cargo" y ocho no refieren.

3. No hay consenso en cuanto a las funciones del gerente: 16 leyes le reconocen funciones ejecutivas o administrativas, y ocho, funciones de representación de la entidad.

4. Quince leyes no tocan el tema de la responsabilidad del gerente; cuatro lo hacen responsable personalmente por sus actuaciones y dos responsabilizan al órgano directivo por las actuaciones del gerente.

\section{Pautas o recomendaciones}

La ley debería considerar la gerencia como una figura opcional u obligatoria de acuerdo con las dimensiones de la EESS (García-Müller, 2006). Hasta tanto no adquiera una amplia complejidad administrativa, la gestión podría ser asumida por los directivos en forma rotatoria y benévola (Hecker, 2008), siempre que estén debidamente capacitados para ejercer sus funciones con propiedad. A partir de determinado umbral, sería obligatorio, en cuyo caso la propia ley debe asignarle competencias propias, de ejercicio privativo, además de las que le pueda delegar el órgano directivo. Se debe precisar su doble relación con la empresa (orgánica y laboral), sus relaciones con los directivos y su régimen de responsabilidad. 
Tabla 1. El gerente en las leyes de economía solidaria de América Latina

\begin{tabular}{|c|c|c|c|c|c|c|c|}
\hline \multirow[t]{2}{*}{ Leyes } & \multicolumn{3}{|c|}{ Naturaleza } & \multicolumn{2}{|c|}{ Competencia } & \multicolumn{2}{|c|}{ Responsabilidad } \\
\hline & Delegado & Cargo & Empleado & Ejecutivas & Representación & Personal & Directivo \\
\hline $\begin{array}{l}\text { Argentina } \\
\text { cooperativas - } 1973\end{array}$ & $\mathrm{X}$ & & & $\mathrm{X}$ & & $\mathrm{X}$ & $\mathrm{X}$ \\
\hline $\begin{array}{l}\text { Bolivia } \\
\text { cooperativas - } 2013\end{array}$ & $\mathrm{X}$ & & & $\mathrm{X}$ & & & \\
\hline $\begin{array}{l}\text { Brasil } \\
\text { cooperativas - } 1971\end{array}$ & & & $\mathrm{X}$ & $\mathrm{X}$ & & & \\
\hline $\begin{array}{l}\text { Colombia } \\
\text { cooperativas - } 1988\end{array}$ & & & & $\mathrm{X}$ & $\mathrm{X}$ & & \\
\hline $\begin{array}{l}\text { Colombia } \\
\text { Mutuales - } 1989\end{array}$ & & & & & $\mathrm{X}$ & & \\
\hline $\begin{array}{l}\text { Colombia } \\
\text { Fondos de } \\
\text { empleados - } 1989\end{array}$ & & & & $\mathrm{X}$ & $\mathrm{X}$ & & \\
\hline $\begin{array}{l}\text { Cuba } \\
\text { cooperativas - } 2002\end{array}$ & & & & $\mathrm{X}$ & & $\mathrm{X}$ & \\
\hline $\begin{array}{l}\text { Honduras } \\
\text { cooperativas - } 1987\end{array}$ & $\mathrm{X}$ & $\mathrm{X}$ & & & $\mathrm{X}$ & & \\
\hline $\begin{array}{l}\text { México } \\
\text { cooperativas - } 1994\end{array}$ & & & & $\mathrm{X}$ & & & \\
\hline $\begin{array}{l}\text { Nicaragua } \\
\text { cooperativas - } 2004\end{array}$ & & & & $\mathrm{X}$ & & $\mathrm{X}$ & \\
\hline \multicolumn{8}{|l|}{$\begin{array}{l}\text { Panamá } \\
\text { cooperativas - } 1987\end{array}$} \\
\hline $\begin{array}{l}\text { Paraguay } \\
\text { cooperativas - } 1994\end{array}$ & $\mathrm{X}$ & & & $\mathrm{X}$ & & & $\mathrm{X}$ \\
\hline $\begin{array}{l}\text { Paraguay } \\
\text { Mutuales - } 2008\end{array}$ & & & $\mathrm{X}$ & $\mathrm{X}$ & & & \\
\hline $\begin{array}{l}\text { Puerto Rico } \\
\text { cooperativas - } 1994\end{array}$ & $\mathrm{X}$ & & & $\mathrm{X}$ & & & \\
\hline $\begin{array}{l}\text { Republica Dominicana } \\
\text { cooperativas - } 1964\end{array}$ & $\mathrm{X}$ & & & $\mathrm{X}$ & & & \\
\hline $\begin{array}{l}\text { Ley Marco para A.L. } \\
\text { - } 2009\end{array}$ & & & $\mathrm{X}$ & $\mathrm{X}$ & & $\mathrm{X}$ & \\
\hline $\begin{array}{l}\text { Ecuador } \\
\text { Economía - Solidaria } \\
2011\end{array}$ & $\mathrm{X}$ & & & $\mathrm{X}$ & $\mathrm{X}$ & & \\
\hline No mencionan & \multicolumn{7}{|c|}{$\begin{array}{l}\text { Cooperativas: Guatemala 1979. El Salvador 1986. Venezuela 2001. Uruguay } 2008 . \\
\text { Estatuto de cooperativas del Mercosur } 2009 . \\
\text { Otras: Ley de Mutuales de Nicaragua 2010. Ley de cajas de ahorro de Venezuela } 2005 .\end{array}$} \\
\hline
\end{tabular}

Fuente: el autor 


\section{Referencias}

Alonso, F. (2001). Órgano de Administración. La sociedad cooperativa en la ley 27/1999, de 16 de julio, de cooperativas. Granada: Comares.

Alonso, F. (2010). El consejo rector y el administrador único de la cooperativa. Derecho de sociedades cooperativas de la Región de Murcia. Pamplona: Aranzadi.

Althaus, A. (1974). Tratado de Derecho Cooperativo. Rosario: Zeus.

Álvarez, J. (2012). Cuando el tamaño importa: una breve revisión a los problemas de una dimensión inadecuada. Revista Cooperativismo \& Desarrollo, 20(100), 234-247.

Álvarez, J., Gordo, M. y García-Müller, A. (2009). Análisis de la política fiscal del sector solidario colombiano, Bogotá, Cootradia.

Ardiles, F. (1979). La Empresa obrera cooperativa. Valencia.

Bastidas-Delgado, O. y Richer, M. (2001). Economía social y economía solidaria: intento de definición. Cayapa, Revista venezolana de Economía Social, año 1, (1).

Celebrón, A. (1998). Efficienza e partecipazione nelle cooperative agroalimentari. Revista della Cooperazione, 1.

Confederación Europea de la Agricultura (CEA). (1968). Estudio Comparado del derecho de la cooperación agrícola en Europa. Suiza: Publicaciones de la CEA.

Ciurana, J. (1968). Curso de Cooperación. Barcelona: Bosch.

Cooperative League on the USA. (1973). Administración moderna de cooperativas. México: Editorial Roble.

Correa, A. (2003). A Responsabilidade Civil e Tributaria das Cooperativas. Cooperativismo e o Novo Código Civil. Belo Horizonte: Mandamentos.

Cracogna, D. y Uribe, C. (2003). Buen Gobierno Cooperativo. Hacia un Código de buenas prácticas. Bogotá: Confederación de Cooperativas de Colombia.
Dávila, R. (2005). Innovación y éxito en la gerencia cooperativa. Casos exitosos de cooperativas rurales de ahorro y crédito. Bogotá: Pontifica Universidad Javeriana.

Durán, A. (2004). El rol de la junta de vigilancia en el sistema de control interno de las cooperativas de ahorro y crédito de América Latina y el Caribe. Documentos para Discusión, (9). San José: DGRV.

Gagliardo, M. (2007). Administración y representación de sociedades comerciales. Buenos Aires: Abeledo-Perrot.

García-Müller, A. (1997). Distribución de competencias en las empresas solidarias. Anuario de Estudios Cooperativos. Bilbao: Universidad de Deusto.

García-Müller, A. (1998). Marco jurídico del Modelo de Economía Solidaria. La Economía Solidaria, una alternativa frente al Neoliberalismo. Bogotá: Colacot-CGTD.

García-Müller, A. (2002). Las mutuales de salud. Cayapa, Revista Venezolana de Economía Social, (4).

García-Müller, A. (2006). Transformaciones necesarias en las legislaciones latinoamericanas y grado de incorporación. Alé-Kumá 25 y 26. Bogotá: Universidad Cooperativa de Colombia.

García-Müller, A. (2008). Bases jurídicas de las políticas públicas sobre cooperativas. Revista Jurídica de Economía Social y Cooperativa, (19).

García-Müller, A. (2009), Instituciones de Derecho Cooperativo, Mutual y Solidario, tomo II. Bogotá: Universidad Cooperativa de Colombia.

García-Müller, A. (2012). Cómo determinar qué entidades forman parte de la economía social y solidaria. Unisangil empresarial, $5(1)$.

Hecker, C. (2008). El dirigente benévolo: su regulación en derecho francés. Revista de Derecho, (223-224).

Henry, H. (2000). Cuadernos de legislación cooperativa. Ginebra: OIT. 
Henry, H. (2002). Lineamientos para la legislación cooperativa. Política y legislación cooperativa, (20). Bogotá: Ascoop.

Issert, J. (1958). Le Droit du Travail dans les Sociétés Coopératives Agricoles. Revue: Coopération Agricole, 55/56.

Kint, J. y Godin, M. (1968). Les Sociétés Coopératives. Brussels: Maison Ferdinand Larcier, S.A.

Lovis, R. (1974). Organización y funcionamiento administrativo de las cooperativas. Nociones de Formación, (5). Ginebra: oIT-Intercoop.

Márquez, V. (2002). Estudios sobre la relación de trabajo. Caracas: UCAB.

Mateo, J. (2005). La legislación cooperativa comparada en las Autonomías: algunos puntos críticos. Zaragoza, Aecoop.

Moirano, A. (2009). Revisión de los originales del libro Instituciones de Derecho Cooperativo, Mutual y Solidario, de Alberto García Müller [documento privado].

Molano, J. (2011). Gerencia solidaria. Modulo VII. Manual de capacitación sobre economía solidaria y desarrollo comunitario. Valencia: Ecosol-Inauco.

Molina, C. (1968). Curso monográfico sobre la Ley General de Asociaciones Cooperativas. [Mimeógrafo]. Caracas: Universidad Central de Venezuela.

Mora, J. (1992). Cooperativismo, lucro y diferenciación profesional. Universidad de Costa Rica, Memorias 1992. San Isidro El General: Universidad de Costa Rica.

Morgado, P. (2012). Reflexiones sobre la ética en el sistema de producción; especial referencia a la economía social. La ética en el sistema de producción: economía social y responsabilidad social empresarial. Navarra: Aranzadi.

Muños, A. (2006). El régimen jurídico contable en las sociedades cooperativas y en las SAT. Cooperativas agrarias y sociedades agrarias de transformación. Madrid: Dykinson.
Nissen, R. (2000). Panorama actual del Derecho Societario. Buenos Aires: Ad-hoc.

Organización Internacional del Trabajo (OIT). (2002). Promoción de las cooperativas. Informe v. Conferencia Internacional del Trabajo. Ginebra: OIT.

Paradis, G. (1993). Rol de la gerencia cooperativa en la reconversión productiva. Reconversión y competitividad cooperativa. San José: ACI.

Parnell, E. (1993). Economía o ética: Sistemi di gestione per risolvere il problema. Rivista della cooperazione, (13).

Pastor, C. (2007). La responsabilidad del órgano de administración de las sociedades cooperativas y su necesaria incardinación en el moderno derecho de sociedades. Revista Jurídica de Economía Social y Cooperativa, (18).

República de Chile (2002). Ley General de Cooperativas.

República de Colombia, Corte Constitucional (1993). Sentencia C-593 de 1993: htpp://gerencia.com/empleados-de-dirección-y-confianza.htm3

Rodríguez, R. y Cedeño, G. (1991). Responsabilidad civil contractual y extracontractual del consejo de administración y el gerente de una cooperativa. Primeras Jornadas de Derecho Cooperativo. San José. Universidad de Costa Rica.

Salvatierra, C. (2011). El rol de la alta dirección cooperativa. s. e.: Lima.

Sánchez, R. (1992). Facultades y deberes del Gerente cooperativo (particular referencia al poder especial). Anuario de Estudios Cooperativos. Bilbao: Universidad de Deusto.

San Pedro, J. (1984). Manual de organización y gestión. Serie Manuales, (11). Buenos Aires: Intercoop.

Sanz Jarque, J. (1994). Cooperación. Teoría general y régimen de las sociedades cooperativas. El nuevo Derecho Cooperativo. Granada: Comara. 
Schneider, J. (1999). Democracia e Participação, Autonomía cooperativa. Saô Leopoldo: Unisinos.

Schujman, L. (1969). Democracia cooperativa contemporánea. Revista de la Cooperación Internacional, 2.

Soveral, A. (2002). A responsabilidade dos membros do conselho de administracao por actos ou omissoes dos administradores delegados ou dos membros da comissao executiva. Boletim da facultade de direito, 8 .

Thomas, E. (1962). Gestión de las cooperativas. Madrid: Aguilar.

Torres, Z. y Maza, N. (2004). El buen gobierno de las cooperativas. Boletín de la Asociación
Internacional de Derecho Cooperativo, 38. Bilbao: Universidad de Deusto.

Vargas, C. (2009). La estructura orgánica de la sociedad cooperativa y el reto de la modernidad. Revista Jurídica de Economía Social $y$ Cooperativa, 20.

Vasquerizo, A. (1998). Distribuciones patrimoniales irregulares al socio en la sociedad anónima. Revista de Derecho Mercantil, (230).

Verón, V. (2009). Tratado de las cooperativas, tomo II. Buenos Aires: La Ley.

Yuri, M. (1956). Cooperativas agrícolas y pecuarias. Manual. Washington: OEA. 